\title{
228 Functional cardiac phenotyping of vasoactive intestinal peptide (VIP) deficient mice by MR microsopy
}

\author{
S David Smith ${ }^{1 *}$, Anthony Szema², Sami Said ${ }^{2}$, Helene Benveniste ${ }^{3}$ \\ From $11^{\text {th }}$ Annual SCMR Scientific Sessions \\ Los Angeles, CA, USA. 1-3 February 2008
}

\section{Introduction}

Mice with deletion of the gene for Vasoactive Intestinal Peptide (VIP) exhibit pulmonary arterial hypertension $(\mathrm{PAH})$ with pulmonary vascular remodeling and RV hypertrophy in the absence of hypoxemia ${ }^{1}$. We hypothesized that these mice would also develop a decreased functional capacity of th right ventricle. We tested this hypothesis using MR microscopy to evaluate right and left heart ventricular volumes and corresponding ejection fractions in VIP-deficient and wildtype (WT) control mice.

\section{Methods}

A total of twelve male mice (10-12 months) were used for the studies; Group $1=$ Control; C57BL6/J male mice $(\mathrm{n}=6)$ and Group $2=\mathrm{VIP}^{-/-}$male mice $(\mathrm{n}=6)$. All animals were anesthetized and breathing spontaneously during the study. The electrocardiogram (ECG), respiratory rate, heart rate and body temperature were continuously monitored (SA Instruments). MR images were acquired on a 9.4 $\mathrm{T}$ horizontal bore Bruker magnet. Short axis bright blood views of the heart were obtained with an ECG gated multi-slice 2D-FLASH gradient echo sequence: $\mathrm{TR}=7.5 \mathrm{~ms}, \mathrm{TE}=2.9 \mathrm{~ms}$, Flip angle $=10^{\circ}$, in-plane-resolution: $0.133 \times 0.133 \mathrm{~mm}^{2}$, slice thickness: $1 \mathrm{~mm}$; interslice gap $=0.5 \mathrm{~mm}$. The heart rate and consequent R-R interval allowed for acquisition of 12 cine frames within each cardiac cycle with the given temporal resolution of $7.2 \mathrm{~ms}$. Image analysis was performed using SEGMENT http://segment.heiberg.se. For all studies, end-systole was referred to as the frame with minimal ventricular cavity volume.

\section{Results}

As can be seen from Table 1, in the WT control mice left ventricular (LV) and right ventricular (RV) ejection fractions $(E F)$ were similar. However, in the $\mathrm{VIP}^{(-/-)}$mice the RV EF was significantly lower than the RV EF of the WT control group. Further, end-systolic volumes were approximately $50 \%$ larger in the $\mathrm{VIP}^{(--)}$mice compared to controls. Figure 1 demonstrates the enlarged end-systolic $\mathrm{RV}$ volume in a $\mathrm{VP}^{(-/)}$deficient mouse. The figure displays two series of MR microscopy short axis cardiac images at the time of end-diastole from a WT control mouse (upper panel) and a VIP ${ }^{(-/-)}$mouse (lower panel) and there is clear visual evidence of a dilated RV in the VIP $^{(-/)}$mouse.

\section{Conclusion}

In conclusion, our preliminary data demonstrate that VIP $^{(-/)}$mice have RV disease phenotypically expressed as increases in RV end-systolic volume and a reduced

Table 1

\begin{tabular}{lllllll}
\hline Mouse Genotype & EDV $(\mu \mathrm{l}) \mathbf{L V}$ & EDV $(\boldsymbol{\mu l}) \mathbf{R V}$ & ESV $(\boldsymbol{\mu l}) \mathbf{L V}$ & ESV $(\boldsymbol{\mu l})$ RV & EF $(\%)$ LV & EF $(\%)$ RV \\
\hline WT $(n=6)$ & $47.0 \pm 7.0$ & $23.6 \pm 2.6$ & $15.9 \pm 3.7$ & $8.8 \pm 3.0$ & $65.7 \pm 8.7$ & $63.1 \pm 12.4$ \\
VIP-/- $(n=6)$ & $43.9 \pm 7.4$ & $32.0 \pm 11.2$ & $16.6 \pm 4.4$ & $19.3 \pm 10.8^{* *}$ & $62.5 \pm 4.7$ & $41.9 \pm 12.4^{*}$ \\
\hline
\end{tabular}

$\mathrm{EDV}=$ end-diastolic volume; ESV = end-systolic volume.

${ }^{1}$ Brookhaven National Laboratory, Upton, NY, USA

Full list of author information is available at the end of the article 


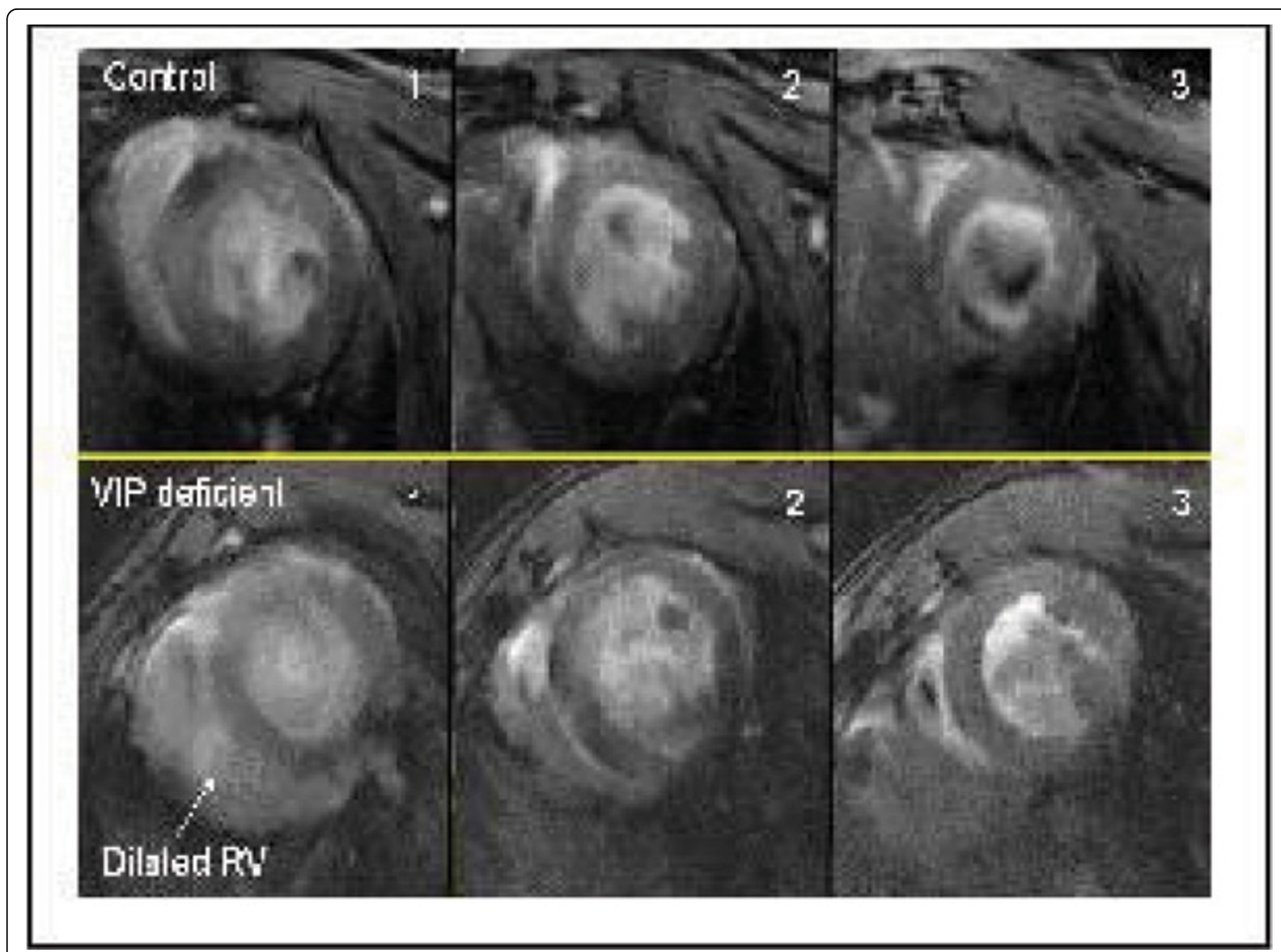

Figure 1 We quantified ventricular volumes from Cardiac CINE MR images to phenotype the cardiac functional capacity in Vasoactive Intestinal Peptide deficient (VIP-/-) mice known to develop pulmonary artery hypertension. Pronounced RV dilation was observed in VIP-/- mice when compared to controls.

RV EF where as the LV is unaffected when compared to WT controls. Studies are underway to characterize the development of RV pathology in $\mathrm{VIP}^{-/-}$mice over time and to examine the effect of VIP therapy on the RV functional capacity in these mice.

\section{Author details}

${ }^{1}$ Brookhaven National Laboratory, Upton, NY, USA. ${ }^{2}$ Departments of Medicine, State University of New York at Stony Brook, Stony Brook, NY, USA ${ }^{3}$ Department of Anesthesiology, State University of New York at Stony Brook and Brookhaven National Laboratory, Stony Brook, NY, USA.

Published: 22 October 2008

doi:10.1186/1532-429X-10-S1-A89

Cite this article as: Smith et al:: 228 Functional cardiac phenotyping of vasoactive intestinal peptide (VIP) deficient mice by MR microsopy. Journal of Cardiovascular Magnetic Resonance 2008 10(Suppl 1):A89.

\section{Submit your next manuscript to BioMed Central and take full advantage of:}

- Convenient online submission

- Thorough peer review

- No space constraints or color figure charges

- Immediate publication on acceptance

- Inclusion in PubMed, CAS, Scopus and Google Scholar

- Research which is freely available for redistribution 